ORIGINAL ARTICLE

\title{
False dichotomies: EBM, clinical freedom, and the art of medicine
}

\section{Parker}

J Med Ethics; Medical Humanities 2005;31:23-30. doi: 10.1136/jmh.2004.000195

According to numerous commentators, clinical freedom, the art of medicine, and, by implication, a degree of patient welfare, are threatened by evidence based medicine (EBM). As EBM has developed over the last fifteen years, claims about better evidence for medical treatments, and improvements in healthcare delivery, have been matched by critiques of EBM's reductionism and uniformity, its problematic application to individual patients, and its alleged denial of the continuing need for clinical interpretation, insight, and judgment. Most of these attacks on EBM and defences of clinical freedom fail. They are based on erroneous understandings of the relationships between inductive knowledge, clinical uncertainty, and action. Evidence based medicine is a necessary condition for clinical freedom, not a threat to it, and EBM is not something to be balanced with either clinical experience or patient preferences. The art and science of medicine are more conceptually and practically connected than the defenders of clinical freedom, whatever they conceive that to be, are willing to admit.

Correspondence to: $M$ Parker, School of Medicine UQ, Herston Rd, Herston, Qld 4006, Australia;

m.parker@uq.edu.au

Accepted for publication 1 March 2005
$\mathrm{E}$ vidence based medicine (EBM) attracts continuing critique, which includes the charge that it will erode clinical freedom, long cherished by physicians as essential to effective practice. In this paper, I provide a brief historical background to EBM, and preface my primary task with a summary of critiques of EBM that I consider sound, in order to indicate that I do not regard it as an unalloyed blessing. I then explore misconceptions about scientific evidence concerning populations and individuals, evidence based guidelines, patient values and welfare, and clinical judgment and authority. The resulting account supports a more robust concept of clinical freedom and accountability, and undermines traditional conceptions of the relationship between the science and the "art" of medicine.

\section{EBM: HISTORICAL BACKGROUND}

EBM and its discontents constitute a current instance of the continuing but counterproductive rivalry between the empiricist and rationalistic traditions in Western culture. Empiricism was well established when Hippocrates made his observations concerning diseases, but the Hippocratic corpus is acknowledged as the earliest formalisation of that spirit for medical practice. Galen, Hippocrates's great interpreter, continued this tradition, claiming for observation a central place in delineating the workings of the body.

Yet Galenic medicine was also strongly rationalistic, putting faith in an intelligible design to the human body. Despite being partly derived from Greek naturalism and empiricism, the tradition initiated by Galen dominated for centuries, due to the acceptance by Christianity of Aristotelian science, which though naturalistic was also teleological, and the church's desire to define more traditional, experience based medical folkways and healing practices as heretical. Both Christianity and medicine in the Dark and Middle Ages shared a commitment to an essentially rationalist model, whereby their universal sets of principles were regarded as true by the necessity of their spiritual (from God) or ancient (from Hippocrates and Galen) authority. ${ }^{1}$ By the later Middle Ages, the Latin medical tradition had concentrated intellectual and social power in the hands of an elite group, whose members deduced practical remedies from the tradition's fundamental axioms, and excluded practitioners of other healing modalities who had not been trained by the official profession within the (by then) developing universities. Students accepted and internalised the tradition as an unquestioned canon.

It was not until the Renaissance that this influential tradition was seriously questioned, having already been shown wanting in contrast to the effectiveness of early "epidemiological" observations and population based responses by European civil authorities in contending with the bubonic and syphilitic plagues as serious threats to public health. ${ }^{2}$ Even by the seventeenth century, however, the medical profession remained as much the appropriator as the instigator of the scientific explosion of the time (French, ${ }^{1}$ pp 157-84). Although medicine had never entirely ignored the empirical side of its activity, it clung tenaciously to old axioms, sometimes in the face of clear evidence of contrary positions. The "allopathic" profession utilised the increasing success of science to further consolidate its authority, ${ }^{3}$ continuing its long public position of allegiance to the interdependence of science, competence, and accountable practice. Subsequently, however, during the nineteenth and into the twentieth centuries, this professional claim became more and more justified, due to the demonstrable efficacy of

Abbreviations: EBM, evidence based medicine; RCT, random controlled trial 
fallible science, in contrast to the infallible medical "science" of the long Galenic night.

Yet the very notion of scientific progress has often been decried over the past forty years. Science and technology, intellectually rooted in Bacon's concept of science as the engine of human betterment and progress (Porter, ${ }^{2}$ p 245) ${ }^{4}$ and in Descartes' mechanical and purposeless conception of matter, ${ }^{5}$ have increasingly come to be seen, not as neutral servants, but as blind, rogue tyrants. Science is said to have effectively stripped human experience of meaning, purpose, and spirituality. ${ }^{6}$ Scientific success is also said to serve the political nurturing of individualism and consumerism, which in turn feed capitalism, globalisation, and related means of exploitation.

Responses to this perceived nexus of science and human exploitation include the consumer movements, attempts to explore and expose the social determinants of health, the increasing popularity of complementary and alternative medicine, and calls for the restructuring of health care. To different extents, these responses have been viewed by allopathic medicine as threats to its authority, and some commentators see allopathic medicine as having resorted to EBM to help reinforce that authority, by regulating the conditions under which doctors speak authoritatively, and to clarify what it is to be a doctor in relation to those who are not (Denny, ${ }^{3}$ pp 253-6).

Although this description is consistent with the way in which organised medicine initially appropriated science and distinguished itself from other practices, it does not accurately depict the relationship between the current profession and EBM, since there is a large difference between the authority conferred by the claims to the truth of a tradition, which are held to be beyond challenge, and that conferred by fallible knowledge. Evidence based medicine has been generated from within the medical profession, in an effort to replace its traditional, historical authority with a better justified basis for scientific and clinical claims. It is the practitioners who resist EBM who represent the rump of medicine's traditional authority, and I will argue that "submission" to the rules of EBM is not a cost that individual doctors must pay, but the core of any meaningful clinical freedom. If EBM's relationships with other aspects of medical practice and health care are correctly understood and applied it will serve society well. ${ }^{7}$

\section{SPUN GOLD? RANDOM CONTROLLED TRIALS AND THEIR DISCONTENTS}

Individual practitioners are encouraged to employ "bedside" EBM in order to offer their patients the treatment with the best evidence in the circumstances that they face, whereas "regulatory" EBM is employed to rationalise practice at the level of health service delivery and to control expenditure. ${ }^{89}$ Critics of EBM will usually have one type or other in mind, but they overlap.

Random controlled trials (RCTs) are accepted as the "gold standard" of methods that deliver the evidence to be applied in clinical care and even higher level evidence accrues from meta-analyses of RCTs that qualify for inclusion. ${ }^{10}{ }^{11}$ Although RCTs produce population data, their unit of ultimate interest is often the individual, whose clinical problem EBM endeavours to help solve. RCTs employ sampling, which requires the use of confidence intervals to indicate the level of certainty with which a particular result may be accepted, and they investigate the effect of an intervention under controlled conditions, aiming to eliminate confounding influences and observer bias.

These virtues may, however, be a mixed blessing. Because knowledge from RCTs is produced without the confounding effects of other variables, it never wholly applies to a particular individual or situation (Dickenson et al, ${ }^{8} \mathrm{p}$ 247). The elimination of confounding factors, including social and political effects, can tend to remove them from focus. ${ }^{12}$ Further, the quantification, which is the hallmark of RCTs, does not eliminate all bias, because even quantitative information can be presented differently, and patients' variable expectations can "shape" information differently. ${ }^{13}$

Those areas where obtaining high quality evidence according to the evidentiary hierarchy of EBM is more straightforward and/or cheaper will be favoured by the requirements for such evidence. Thus, RCTs are utilised by drug companies to produce level 1 evidence ${ }^{10}{ }^{11}$ for new drugs, whereas areas in which it is more difficult to use RCTs may suffer. ${ }^{14}$ Rather than starting with healthcare priorities and setting the research agenda on that basis, the system tends to be inverted by EBM, with research often being performed as much for commercial as for scientific and health reasons. Although authorities that promulgate the principles and hierarchies of EBM evidence also include factors such as economic considerations (NICE, ${ }^{11}$ ch 8) and stakeholder input (NICE, ${ }^{11}$ ch 14), hard numerical evidence is seductive, particularly to funders of health care. There appears to be little systematic inquiry into what areas are poorly researched, how research priorities are identified, and who runs research (Denny, ${ }^{3}$ p 255).

Consequently, so called "orphan fields" such as physiotherapy, psychotherapy, psychology, occupational health, ${ }^{15}$ palliative care, psychiatry (Dickenson et al, ${ }^{8}$ pp 252-3), and chronic disease ${ }^{16}$ compete for funding from a position of disadvantage. A skew toward therapeutic interventions and away from preventive ones, and to pharmacological ones and away from complex social care, are significantly driven by EBM methodology and the related financial rewards.

Research is increasingly a business, and as governments and research institutions secure more financial support from the private sector research may be expected to be increasingly restricted to biological factors that are readily modified by individual treatments such as drugs, rather than including social and cultural factors in the determination of morbidity and mortality. ${ }^{12}{ }^{17}$ Measured risk factors for disease usually do not include socioeconomic deprivation or ethnicity, so that recommendations for treatment often do not reflect the true state of affairs in different communities. The focus on biological risk factors may also lead to population trends being seen as merely the sum of individual cases. Social factors cannot then be seen as causal factors in disease. When social and cultural "confounders" are controlled for, which is the confounder, the social or the biological factor? Trials that focus on the lifestyles of individuals, rather than social and cultural factors, tend to be favoured by modern polities, which are less motivated to redress social inequities and keener to shift responsibility to individuals, who come to be seen to have a number of obligations including self care and self monitoring programmes, and the acceptance of different medical or surgical interventions. The methodologies favoured by EBM tend to categorise patients as individual consumers who need the best evidence to make healthcare decisions, but this avoids the analysis of more politically and socially contingent categories, and EBM is consequently seen to serve the purposes of healthcare markets rather than the health care of people in their particular communities.

Rogers has pointed out that both in formulating research agendas and in the recruitment for and performance of research, gender biases cannot be attributed to EBM as such, since meta-analyses and systematic reviews are still largely appraising the findings of "pre-EBM" research. Nevertheless, EBM may well be found wanting for not adhering to its stated aim of identifying gaps in the research base, and by 
failing to point to such biases, and to advocate for their redress (Rogers, ${ }^{17}$ p 62).

Another problem is an effect which regulatory EBM may have on bedside practice. In wanting to get the best value for money, health administrations increasingly look for compliance with guidelines and the achievement of targets-for example, for immunisation or Pap smear screening. Linking quality payments to providers with compliance with guidelines and clinical governance agendas is potentially problematic, because if the failure to achieve targets means loss of income for providers, then coercion of patients by providers becomes a real possibility (Slowther et al, ${ }^{14} \mathrm{p} 153$ ). ${ }^{18}$

These observations deserve the critical attention they are now beginning to receive. Presentation bias can occur whether what is presented is evidence based or not, so this is not a strong criticism of EBM itself. There is little doubt, however, that the bald evidentiary hierarchy of EBM favours drug trials over trials of other therapeutic methods. The emphasis on individuals and lack of attention to psychosocial, economic, and cultural factors has the effect of unbalancing the weight of responsibility between individuals and polities. Together, these processes threaten to leave orphaned fields without the strategic benefit of high level evidence.

Advocates of EBM often claim that it is only the "best available" evidence that needs to be used in relation to any clinical question, and so the areas that are less effectively researched using RCTs are not disadvantaged, because whatever is the best available evidence can be used. This is somewhat disingenuous. If the best available evidence is of a lower status than what is possible in principle, it will still be regarded as less important and persuasive. What is needed is a revision of the evidentiary hierarchy, which would serve two purposes. Firstly, it should not throw the RCT baby out with the bath water-statistically, RCTs are the best sort of evidence. It is also possible to establish evidence at conventionally high levels, even in some of the orphan areas-for example, evidence based clinical practice guidelines for the psychosocial care of adults with cancer have recently been developed and approved by Australia's National Health and Medical Research Council. ${ }^{19-21}$ Secondly, the evidentiary hierarchy should be modified to account for the relative difficulties of obtaining different sorts of evidence in different fields, and for the range of factors beyond the biomedical, which are involved in illness causation and management. No easy task, but EBM should concern itself with developing multiple axes of evidentiary value to account for the differences between fields of medical inquiry.

\section{SCIENTIFIC IRRATIONALISM AND THE CRITICISM OF INDUCTION}

"We can always be sceptical about inductive evidence"22 (my emphasis). The negative spirit of this trivially true statement pervades much of the literature that is critical of EBM. A generally sceptical spirit about inductive knowledge is difficult to square with the fact that critics of EBM do not object when trials are ceased on ethical grounds. Like everyone else, they accept that the negative outcomes are truly the result of the trial, despite the fact that the results, like all trial results, are "only" inductively true.

The late Australian philosopher David Stove pointed out that whereas many eighteenth and nineteenth century philosophers exaggerated the certainty and extent of scientific knowledge, the "fall" of Newtonian physics at the opening of the twentieth century saw philosophers of science adopt a much less optimistic outlook, aiming to avoid the hubris of late modernity. ${ }^{23}$ According to Stove, both the logical positivists and the "scientific irrationalists" accepted the fallibility of induction and the permanent possibility of the falsity of scientific theories, but the irrationalists transformed Hume's logical scepticism about induction into a generally sceptical attitude toward it. Now, no empiricist believes that scientific conclusions can be deduced from the observations that appear to support them, but recent scepticism about induction is far stronger than that-this takes the position that there is no compelling reason to accept inductive conclusions as objectively true, not that inductive conclusions can be false.

Critics of EBM usually do not take up quite such an explicit antiscience stance. They are usually more concerned with the relationships between epidemiological findings and their significance for individual patients. Just to have these concerns presupposes an acceptance of the epidemiological findings. Nevertheless, there seems to have been an overshoot from the excessive hubris of the eighteenth and nineteenth centuries about the certainty of science, to a generally and unreasonably sceptical mood about the importance, relevance, and status of scientific progress, the accumulation of scientific knowledge, and the possibility of applying this knowledge to individuals.

This leads to mistakes and misunderstandings-for example, some commentators want to distinguish qualitative research from science. Downie and Macnaughton suggest that although we cannot generalise qualitative research by induction, it can be generalised by our identification of the situation with universal features of human emotions. ${ }^{24}$ However, the assumption about the universal features of human emotions is a scientific theory itself, inductively generated. Moreover, qualitative research can be made evidence based..$^{25}$ That said, it is also true, as we have seen, that the current hierarchy of EBM methods tends to define much qualitative research as of lower evidentiary status, despite its appropriateness to many research questions.

Another criticism of EBM is that inductive judgments are covertly normative: since inductive claims are never certain, they imply judgments about the acceptability of confidence intervals, and if judgments of acceptability are not shared and understood, there can be conflict over the firmness of the medical "facts" that are established (Downie and Macnaughton, ${ }^{24} \mathrm{p} 10$ ). I believe this substantially overstates the potential for conflict, since there is widespread agreement about the significance of different confidence intervals. ${ }^{26}$ Although it is true that judgments of acceptability can differ, we have already seen that such judgments do not interfere with decisions to cease clinical trials when the evidence points to serious problems.

Further, according to recent accounts in the philosophy of science, all factual claims are infused by values. In order to avoid misapplying these "factual" claims and harming patients who do not agree with the values they covertly import, Robert Veatch has suggested adopting the recommendations of the expert who is closest in value orientation to the patient, ${ }^{27}$ and that, for policy purposes, the average view of the experts should be adopted. ${ }^{28}$ This seems to say too little by claiming too much. On this theory, no factual claim will be value neutral, yet we generally manage to get by in life without excessive interference in our fact finding and fact expressing communications from different perspectives and value positions. An expression such as "high risk" may be inappropriate for patients who are not particularly risk averse, but risks can be presented in a number of accessible numerical ways, allowing patients to consider the evidence, relatively untainted by someone else's unwitting evaluations (see next section).

Finally, it has been argued that RCTs cannot be the gold standard for EBM, since they explore non-causal hypotheses, and tell us nothing about the mechanisms of disease (Downie and Macnoughton, ${ }^{24}$ pp 7-8, 36). Being a species of statistical 
assessment of constant conjunctions, they are inductive inferences, not explanatory accounts. This status is assumed by some critics to be inferior to pathophysiological inferences and theories. The function of RCTs is surely, however, to test the efficacy of reasonably plausible hypotheses, and to help develop an increasingly coherent, albeit incomplete, system of general laws, rather than supplying a complete and consistent system of knowledge. ${ }^{29}$ Furthermore, medical history is littered with cases where the therapeutic predictions of apparently sound pathophysiological theories have turned out, on empirical testing, to be entirely wrong. ${ }^{30}$ Recall the Galenic tradition which privileged axiomatic principles from which medical treatment was deduced, but which was seldom empirically tested. Neither plausible pathophysiology nor empirical testing is alone sufficient for rational medical practice. To think of them as competitors for gold standard status misconceives the complementary roles of causal and inductive reasoning. ${ }^{31}$

\section{POPULATIONS AND INDIVIDUALS: A FALSE DICHOTOMY?}

Not surprisingly, attempts to extrapolate from general evidence to individuals did not suddenly arise with the advent of EBM..$^{32}$ Aristotle believed the best treatment for an individual would be given by a physician who was familiar with common facts. ${ }^{33}$ In the latter part of the seventeenth century, the English physician Thomas Sydenham argued that diseases should be categorised by distinguishing their constant and adventitious features. Like EBM advocates today, he was criticised for shifting doctors' attention away from their individual patients, making them less empathic, and discouraging patients' compliance. ${ }^{34}$ Nevertheless, although EBM is not the first movement in medicine to be challenged over the application of general findings to individuals, difficulties with the application of general findings have come into sharper focus in response to EBM's refinement of method.

Outcomes assessments are probabilistic; they cannot guarantee efficacy in individual cases. This is the way of inductive knowledge, but a number of commentators make a more radical split between ideal population data and applicability to individuals..$^{35}$ The individualistic focus of the clinician and the community orientation of the epidemiologist has, for example, been described as the source of the "incommensurability" between the two disciplines. ${ }^{36}$ Tanenbaum has argued that: "Ironically for the outcomes movement, empiricism is especially susceptible to the influence of a physician's past experience, because probabilistic findings, however rigorous, are only of likely effectiveness over large populations" ${ }^{37}$ Others have suggested that "even bedside EBM is based on an average estimate of effects, derived from population based RCTs whose relevance to the individual patient is not completely (or even loosely) predictable..." (Dickenson et al, ${ }^{8} \mathrm{p} 247$ ). There is more than a whiff of scepticism about induction here. Such radical generalisations challenge the notion that statistical power is just about how well population data applies to individuals, and the probability with which we can make important predictions for patients.

Other observations are simply logically incorrect. Why would one conclude, as one commentator does, from the facts that individual care emphasises autonomy, patient centredness, and serving particular interests, whereas population health concerns aggregated groups of goods and utilitarianism, that there is an implicit conflict between the ethics of individual care and the ethics of population health (Rogers, ${ }^{18}$ pp 278-81)? Does the knowledge gained through population studies not serve the interests of individual patients? Despite the view that the uncertainty inherent in risks makes their application to individuals problematic, probable risks are properties of individuals. Not to ascribe such properties to individuals, when the evidence is good, runs the risk of underestimating the importance of the risk, fails to respect patient autonomy, and may result in some individuals suffering harm.

Another group of objections to the link between population studies and their application to individuals concerns the contrast between the research environment (particularly when it involves RCTs), which is oversimplified and artificial, and clinical settings, which are complex and uncertain (Downie et al, ${ }^{24} \mathrm{p} 46$ ). This distinction is used to contrast specialist and general practice settings, and to suggest that the evidence from population studies is less applicable to the generalist setting, because there the patients are more complex, with multiple pathologies and more uncertain diagnoses (Rogers, ${ }^{18}$ p 279) as well as there being more compliance issues and unquantifiable factors (Slowther et al, ${ }^{14}$ pp 151-2), compared with those in trials and in specialist settings. Patients who attend specialists are said to have more EBM-amenable clinical problems. Guidelines concerning particular problems are, however, no more or less applicable to complex patients than straightforward ones, just as excluding people with comorbid conditions from trials makes the resulting guidelines no more or less applicable to those people, in terms of the conditions that are the focus of the trial. With the obvious proviso concerning causally interrelated conditions, it does not follow, from the fact that people with comorbid conditions are excluded from RCTs, that EBM guidelines are inapplicable in the care of people with such comorbidities (Rogers, ${ }^{12}$ p 142). Complexity makes management more difficult, but does not of itself render trial data irrelevant to different sets of patients.

Far from being irrelevant or marginally relevant to individuals, population data must be effectively presented to them in order for adequately informed decision making to occur. Levels of risk can be presented by way of a range of verbal, pictorial, and graphic illustrations, analogies and metaphors, and statistics. The NNT (number needed to treat) is a straightforward strategy, which most people will understand, and which fulfils the ethical imperative of doctors to accurately convey to patients both the degree of risk and the degree of uncertainty that the trial data provide (Strauss

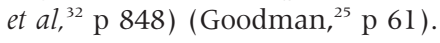

The obligation to link individual patient care with trial data also has a logical grounding. Individual characteristics (apart from patients' preferences), which are not anchored in some more widely occurring pattern, cannot be action guiding because clinical decisions must be made for good reasons, and reasons appeal to other cases. The elimination of confounders and individual differences in trials does not render the trial data irrelevant to individuals; the data is applicable to the extent that an individual shares the trial characteristics under scrutiny. ${ }^{38}$

\section{THOU SHALT FOLLOW THE GUIDELINES}

EBM allegedly constrains and erodes clinical freedom by insisting that better practice will result from following evidence based guidelines. Guidelines are thought to depart from Sackett's suggested integration of the best external evidence with individual clinical expertise and patient preferences $^{39}$ because they present didactic instructions, which leave little room for patient choice (Rogers, ${ }^{18}$ pp 2834). Following guidelines is said to be time consuming, and to distract doctor and patient from other important aspects of the consultation, such as understanding the meaning of the problem for the patient. ${ }^{40}$ Guidelines include value judgments, such as the balance between treatment side effects and survival rates, which are usually implicit, but the values 
of patients are not usually represented in the guidelines (Willems, ${ }^{40} \mathrm{pp} \mathrm{161-2).} \mathrm{Finally,} \mathrm{it} \mathrm{is} \mathrm{considered} \mathrm{likely} \mathrm{that}$ guidelines will have a problematic role in court, with some commentators predicting an unreasonably high status for them, and decisions to act contrary to, or somewhat differently from, a guideline needing justification and detailed documentation (Little, ${ }^{22} \mathrm{p} 113$ ).

It is not surprising that the prescriptive format and function of guidelines is thought to threaten both clinical freedom and patient values, despite the frequent protests from the EBM camp that guidelines are only guidelines. Even if, as in France, guidelines are prepared by specialists and family physicians working together, or, as in Holland, hospital and general practice versions of the same guideline are developed, dissatisfaction remains (Willems, ${ }^{40} \mathrm{pp}$ 154-7). Even the fact that a significant portion of medical treatment continues to be of no proven effectiveness does not dispel the perception of unreasonable prescriptivity, exemplified by phrases such as "changing behaviour" in the literature addressing barriers to the uptake of guidelines. ${ }^{41} 42$

These objections to the development and implementation of guidelines are generally not well thought through. Clear guidelines will tend to increase, not decrease, the time/ efficiency of consulting. Including active verbs rather than vague recommendations, in order to make guidelines more behaviourally specific may increase some clinicians' perception of prescriptivity, but this depends on the actual wording. Active phrases such as "Offer cognitive behavioural therapy" or "Give information about" or "Offer a choice about" conserve the crucial element of patient choice, and should facilitate improved deliberations about the choices to be made. $^{42}$

Objections concerning the inclusion of value judgments in guidelines are overstated. While a trade off between benefits and risks of treatment is certainly a value judgment, it does not follow that we ought to try to represent patient values in the guidelines themselves. If the implicit value judgment contained in a guideline makes it more than a straightforward factual statement, the inclusion of patient preferences in guidelines themselves (however that is to occur) will have the same effect. Whose preferences should be included? Furthermore, value judgments implicit in guidelines are no different from those implicit in any treatment recommendation. If a doctor advises a patient to take a particular antibiotic for tonsillitis, there is a legal obligation to explain the trade off between probable risks and benefits built into the recommendation, whether the recommendation derives from a guideline or from the doctor's memory.

What of the legal role of guidelines? It is true that nowhere have guidelines replaced expert testimony in the courts. ${ }^{43}$ They will, however, undoubtedly play an increasingly important role in providing courts with the information they need to make decisions concerning the standard of care, with the caveat that, like experts, guidelines vary in their evidentiary reliability. It is important to distinguish between good and bad reasons for acting outside an accepted guideline. At one extreme, a patient's preference for no treatment will clearly make a guideline irrelevant, and treatment would constitute an assault rather than negligence! At the other, however, when the goal of treatment is not in dispute, departure from a clinically relevant guideline calls for justification.

It could be thought that the legal status of guidelines will significantly depend on whether a jurisdiction has retained or rejected a Bolam-like principle, whereby negligence may be defended by appeal to what a respected body of practitioners would have done in the circumstances. ${ }^{44}$ The distinction is being increasingly diluted by the evolution of EBM itself, however, as traditional medical authority is challenged by the requirement for reliable evidence. The courts will continue, as always, to rely on expert testimony, but since the change is internally driven, the nature of expert testimony itself will change.

\section{PATIENT VALUES AND PREFERENCES}

EBM is said to limit the role played by patients' values and preferences and it is consequently criticised for reimporting a generalised paternalism into the patient/doctor relationship. Rather than reducing paternalism by limiting the capacity of authoritarian doctors to do what they like, under the influence of EBM, expertise and power remain in the hands of the doctors, who interpret the raw data in order to act. In their enthusiasm for EBM, physicians may replace the paternalistic mantra of "doctor knows best" with the mantra of "the evidence knows best" (Slowther et al, ${ }^{14} \mathrm{p} \mathrm{152)}$. Dickenson and Vineis suggest that paternalistic doctors may be tempted to push patients toward the treatment they regard as proven by EBM, and that even for doctors who are determined not to be paternalistic, EBM may reduce patient choice through its logical structure, since the patient may not even learn of "wrong choices" if guidelines have already eliminated them from the consultation (Dickenson et al, ${ }^{8}$ p 249). Although the specific target of these criticisms is EBM's constraints on patients' preferences, clinical freedom is also affected, since anything which limits the negotiation between doctor and patient arguably reduces the role and responsibility of the doctor.

One of the suggestions to rectify the problem of marginalising patient preferences is to include them in the preparation of guidelines, and/or to build the interests of all stakeholders into epidemiological studies. Little sees this as helping to reflect both reductionist and narrative accounts of truth, and helping to include those values that ground the health endeavour (Little, ${ }^{36}$ pp 1142-4). The Netherlands has developed these models to the greatest extent, with patient organisations encouraged and funded to contribute to the development of guidelines, ${ }^{45}$ setting priorities for research, and incorporating "non-clinical" values in the conclusions drawn from meta-analyses (Dickenson et al, ${ }^{8} \mathrm{p} 250$ ). Another suggestion is that patient preferences will vary in their importance according to the degree of "doubt about the best course of action" ${ }^{46}{ }^{47}$ Even some EBM stalwarts, in attempting to justify their position, have stated that in different situations, different things, including patient preferences, will assume greater or lesser importance. ${ }^{48}$

What can be made of these claims? Inherently paternalistic doctors will paternalise their patients, whether they utilise EBM or not, but the stronger claim is that EBM's logical structure and authoritativeness encourage paternalism. I have argued above that although the facts of EBM may be, to a variable extent, infused by values, risks can be presented in a number of accessible numerical and metaphorical ways and that the logical structure of guidelines and attention to their wording can conserve or even augment patient choice. There are also legal obligations to fully inform patients of their options: but should values be deliberately worked into the development of guidelines? This may well be an ill conceived aim.

First, what evidence and reasons do we have for supposing that EBM is better at preventing "wrong choices" emerging than a medical culture that allows for greater clinical freedom? There has always been a "best treatment". Second, the fact that guidelines smuggle in normative judgments, because efficacy is premised on the basis of a particular outcome or goal, is of limited significance. There is broad general understanding and agreement on the appropriateness of the routine goals of medical care. Treatment advice and guidelines all have the logical structure of hypothetical imperatives, such that-for example, "If you 
want to reduce your risk of stroke by $30 \%$, then take one of this group of drugs". Critics of EBM do not explain how guidelines are any more didactic or prescriptive than other forms of treatment advice, particularly now that doctors are no longer invested with the degree of social authority they once had. On the contrary, by setting medical advice apart from the doctor herself, in guideline format, it might reasonably be said that EBM better allows for the expression and discussion of patient preferences by doctor and patient, as co-interpreters and co-contextualisers of the data provided.

Third, although including the concerns of the community in determining which research questions ought to be pursued, and encouraging the participation of patient organisations in developing guidelines, are both highly commendable initiatives, these are different from building patient preferences into the guidelines themselves. If patient preferences are understood as the self determined wishes of individual patients in respect to treatment options, this proposal is perplexing. By definition, such preferences can only be put into practice within the doctor/patient relationship, in response to information presented. Those who suggest that guidelines extinguish or threaten patient preferences offer no helpful guidance as to how the preferences are to be incorporated into guidelines, which are then submitted to doctors for use within the one to one relationship.

Finally, the idea that patient preferences will vary in their importance according to the degree of doubt/certainty about the best course of action misunderstands completely the status of patient preferences and their proper relation to treatment advice. The idea of a single best course of action is just what critics of EBM are keen to deconstruct, and it is in these cases that they should be more vigilant about the threat to patient preferences. In cases where patients refuse treatment, their preferences will certainly be more apparent than when they agree to follow medical advice. However, consenting to recommended treatment just as clearly puts into practice a preference as refusing it, because consenting to treatment is to authorise it. To suggest that the importance of patient preferences varies according to the situation is a significantly greater threat to patients' interests than the risk of patients' preferences being excluded by evidence based guidelines.

EBM is thus falsely accused of constraining patients' and doctors' freedom by limiting the role played by patients' values and preferences, and for reimporting paternalism into the doctor/patient relationship. We have no reason to accept that the failure to incorporate patient values into clinical decisions is a failure of EBM (Goodman, ${ }^{25}$ pp 17-18).

\section{CLINICAL FREEDOM, CLINICAL JUDGMENT, AND ACCOUNTABILITY}

It is difficult to obtain a definition of clinical freedom, even from those who defend it, although the following conceptual relationships are often supported. Clinical freedom is frequently said to depend on clinical judgment and experience. These, in turn, involve a degree of intuitive knowledge, analogical reasoning, and causal and temporal reasoning about disease processes, all of which employ less quantitative information than is the currency of EBM (Gifford, ${ }^{26}$ p 170). Clinical judgment is sometimes discussed in terms of irreducible particulars or intuitions, which are not captured by rules, but by pattern recognition and the perceptual holism achievable by those with sufficient experience. ${ }^{49}$

According to a strong theme in writings on clinical judgment, it is a species of "practical wisdom", which is considered to be both objective and derived from hard won experience. Here is a typical summary:

"Good doctors use their personal judgment to affirm what they believe to be true in a particular situation. Their knowledge is not purely subjective, for they cannot believe just anything; and their judgment is made responsibly and with universal intent, ie they take it that anyone in the same position should concur. It is practical wisdom.... Here medical practice as art and science converge" (Saunders, ${ }^{46}$ p 70).

This is a traditional picture, with the practically wise doctor dispensing advice and treatment in particular situations, on the basis of intuition, experience, and attention to particulars. Mysteriously, it concedes that doctors in the same situations should reach the same clinical conclusions, albeit on the basis of knowledge, which, although not purely subjective, must be at least somewhat so. If doctors are to arrive at the same conclusions, just what is supposed to be happening when the art and science of medicine converge, and what does this say about clinical freedom?

Clinicians resent EBM's intrusion because they consider that it reduces their clinical discretion, but the better view is that they should use EBM to review and revise their clinical beliefs, since EBM is not remote from the clinicians' world but essential to it. Clinical judgment should be viewed as the critical faculty, employed in the face of uncertainty, used to reduce conceptual biases, to disclose uncertainty to patients, and to encourage the physician's own learning (Goodman, ${ }^{25}$ pp 131-2). Continuing uncertainty demands, not an appeal to clinical experience, but an insistence on more and better evidence. By contrast, because patients so often get better or worse on their own, in spite of much that we do, traditional clinical experience is a poor judge of what works and what does not. ${ }^{30}$

Not altogether surprisingly perhaps, EBM advocates themselves sometimes get things the wrong way round by overcompensating for the backlash against EBM-for example, they often confer a high status on clinical expertise. The crucial point is that clinical expertise is not epistemically prior to evidence based knowledge, but is informed by it.

Clinical expertise and judgment inhabit a black box. If clinicians make judgments in a way that cannot be specified in terms of rules, statistical data, and probabilities, but by looking carefully at the details of the individual case, comparing it with similar, familiar cases, and using intuition built up from years of clinical experience, what is actually happening? Are they relying on sound reasons about a particular patient, or on arbitrary factors such as procedures learned as students but experienced subjectively as clinical judgment? (Gifford, ${ }^{26}$ pp 169-70). The extent to which clinical judgment is "what clinicians say they are doing when they aren't able to do much more than guess" (Gifford, ${ }^{26} \mathrm{p}$ 168) remains unclear. Most clinicians, of course, will strongly reject the idea that they ever guess things, but because there is good evidence of wide variations in clinicians' estimates of pretest probabilities of disease based on presenting clinical scenarios-for example, ${ }^{50}$ there is a strong argument for improving clinical decision making through validated decision rules and other means. ${ }^{51}$

EBM advocates and critics will agree that the telos of clinical freedom, however it is defined, is the good of patients, but the recalcitrant allegiance to the traditional and opaque idea of clinical freedom works against this moral imperative. Traditional clinical freedom and discretion depend on the persistence of erroneous beliefs about the connections between inductive knowledge, evidentiary 
uncertainty, clinical experience, and patient preferences. If clinical freedom is directed toward the good of patients, who must trust doctors to exercise it in their interests, then it deserves a much more rigorous analysis than doctors and organised medicine have so far been prepared to give it. Just as trust is a necessary component of the doctor/patient relationship, clinicians must trust the epidemiologists and the meta-analysts, since clinicians have no hope of being independent self informers on pain of the hubris of claims to infallibility (Goodman, ${ }^{25}$ pp 35-6).

According to Philip Pettit, the concept of freedom requires that three things must hold:

The first is that the agent can be rightly held responsible for what he or she did; if the action was free then there can be nothing against thinking that the agent should have to answer for it. The second is that the action freely chosen is one that the agent can own, thinking: this bears my signature; this is me. And the third is that the agent's choice was not fully determined by at least certain sorts of antecedents; it was not fully determined-for example, by a hypnotic suggestion or an unconscious complex or childhood conditioning. ${ }^{52}$

Pettit considers this "responsibility connotation" as the most satisfying account of freedom, all things considered. The idea certainly seems appropriate in the case of clinical freedom. If we agree that clinical freedom is centrally concerned with the good of patients, and that any authority worth respecting should be epistemically justified in terms other than its own status, then the responsibility that goes with clinical freedom must involve adherence to the principles of EBM. To "submit" to the guidance of EBM is to take responsibility for one's beliefs about patient welfare. Patient welfare depends, in the end, on patient preferences, which are ethically prior to any scientific truths that apply to the patient. That said, the notion of a preference includes what the preference is about, and patients must grapple with what can be meaningfully said about them from the scientific point of view before they can express any meaningful preference.

\section{ART AND/OR SCIENCE?}

In advancing their causes, EBM advocates and critics often agree that the art and the science of medicine need to be balanced, though for different reasons. Advocates do not wish to be perceived as hardnosed number crunchers who make no room for clinicians' experiences and patient preferences, so they allow for some version of clinical wisdom, or at least for a greater role for context and preferences. ${ }^{7}$ Most critics are willing to consider statistical evidence, albeit in some of the questionable ways discussed here, which partly serve the purpose of defending tradition and clinical autonomy. Consider Boyle and Callahan's explanation of physicians' objections to the dominance of EBM, and their conceptualisation of the relationship between the science and art of medicine:

\footnotetext{
"Is medicine science or art? The obvious answer is that it is both - as it has always been - and that the real question is how to find the right balance between them...The moral objections some physicians voice suggest, upon further analysis, that the present science of medicine needs to be augmented with other kinds of considerations, that, for example, information that a skilled physician can observe in a moment of clinical judgment needs to be added to the scientific data" ${ }^{\prime 53}$
}

\begin{abstract}
"At some point, however, if the findings of the outcomes data are strong and compelling, there may be no reasonable course other than to restrict choice and override the claims of experience or patient uniqueness. At some point, science will have to push aside art, however unpleasant this might be" (Boyle and Callahan,, pp 11-13).
\end{abstract}

This conception of balance, and the residual disagreements about the extent to that medicine is art or science, rely on the kinds of distinctions that have been shown above to be highly dubious, and the logical end point of such a conception appears to be a worrying return to the paternalism that champions of clinical freedom claim to avoid. Science and art do not cleave along the plane that separates quantitative and qualitative considerations, and clinical experience ought not to be viewed as distinct from, and therefore as capable of balancing, scientific evidence. It is therefore counterproductive to invoke the "art of medicine" to resist the idea that the science is all there is (Goodman, ${ }^{25}$ pp 95-7), because this will militate against the importance of continuing to reduce uncertainty. Individual characteristics, procedures for interpreting meaning, and "clinical expertise" should not balance science, because they do not vary in importance according to how dependable the science is. Similarly, it is misleading to suggest that patients cannot attend to scientific evidence because it is based on a different set of values from theirs, or that evidence and personal testimony of illness are alternatives, between which patients can choose in their deliberations and decision making. ${ }^{21}$

Clinicians resist the reduction of medical practice by those who want to "analyse everything" and who undervalue "tacit" clinical knowledge. ${ }^{54}$ This may be motivated by some deep sense of the loss of meaning and purpose in life at the hands of science, but it may equally be because the exercise of sophisticated judgment confers authority, commands respect, and provides satisfaction (Nelson, ${ }^{49} \mathrm{p}$ 197), and also because of the unwillingness to relinquish the persona, the power, and the mystique of traditional professionalism (Parker, ${ }^{38} \mathrm{p}$ 279). If, however, the foundation of clinical freedom is the good of patients, then the art of medicine is better interpreted as the various skills brought to bear on making clinical decisions, and these are much closer to the skills required to employ good evidence than to the mysterious ones of an arcane tradition. We are right to reject clinical expertise and the art of medicine as species of intuition, as ineffable entities beyond rational analysis, because no link can be made between intuition and accountability. If this is right, the tension between art and science, and the need to balance them, collapses. We do well to remember that the Greek term "art" referred to anything that could be taught and learned, and that, according to Plato, Art proceeds by rational principles and rules. ${ }^{55}$

\section{CONCLUSION: EBM, CLINICAL FREEDOM, AND RESPONSIBILITY}

EBM is a necessary condition for clinical freedom, not a threat to it, as long as clinical freedom is correctly conceived in its connection with accountability. As I have argued elsewhere, clinical freedom consists in faithfully presenting what is imposed by the reason of science, engaging the patient in assigning his or her meaning to what is offered, and negotiating management choices in the context of the patient's values and preferences. ${ }^{38}$ The currency of medical practice is inductive knowledge, and such knowledge is subject to different degrees of uncertainty. If there is such a thing as the art of medicine, it concerns what we do, in collaboration with our patients, with uncertain knowledge, not what is done in spite of it. 


\section{REFERENCES}

1 French R. Medicine before science. Cambridge: Cambridge University Press, 2003:34-126.

2 Porter R. The greatest benefit to mankind. London: HarperCollins, 1997:122-7.

3 Denny K. Evidence based medicine and medical authority. J Medical Humanities 1999;20:249-51.

4 Porter R. Flesh in the Age of Reason. London: Allen Lane, 2003:8.

5 Descartes R. Discourse on method and the meditations. Harmondsworth: Penguin, 1968.

6 Little M. Cartesian thinking in health and medicine. In: Baume P, ed. The tasks of medicine. Sydney: Maclennan and Petty, 1998:75-95.

7 Guyatt G. Evidence based medicine has come a long way. BMJ 2004:329:990-1.

8 Dickenson D, Vineis P. Evidence based medicine and quality of care. Health Care Anal 2002; 10:243-4

9 Muir Gray JA. Evidence based policy making. BMJ 2004;329:988-9.

10 National Health and Medical Research Council. A guide to the development, implementation and evaluation of clinical practice guidelines. Canberra: NHMRC, 1998, appendix B:56. http://www.health.gov.au/nhmrc/ publications/pdf/cp30.pdf (accessed 3 Dec 2004)

11 National Institute of Clinical Excellence. Guideline development methods. London: NICE, 2004, ch 7. http://www.nice.org.uk/pdf/ GDM_Chapter7.pdf (accessed 5 Dec 2004)

12 Rogers W. Evidence based medicine and justice: a framework for looking at the impact of EBM upon vulnerable or disadvantaged groups. J Med Ethics 2004;30: 142-4.

13 Kee F. Patients' prerogatives and perception of benefit. BMJ 1996;312:958-60.

14 Slowther A, Ford S, Schofield T. Ethics of evidence based medicine in the primary care setting. J Med Ethics 2004;30:153-4.

15 Vos R, Willems D, Houtepen R. Coordinating the norms and values of medica research, medical practice and patient worlds - the ethics of evidence based medicine in orphaned fields of medicine. J Med Ethics 2004;30:166-70.

16 Vlieland TPM. Managing chronic disease: evidence based medicine or patient centred medicine? Health Care Anal 2002;10:289-98

17 Rogers W. Evidence based medicine and women: do the principles and practice of EBM further women's health? Bioethics 2004;18:1, 50-71.

18 Rogers W. Is there a tension between doctors' duty of care and evidence based medicine? Health Care Anal 2002;10:277-87 at 284.

19 National Cancer Control Initiative. Guidelines for psychosocial care. Melbourne: NCCl, 2003, http://www.ncci.org.au/projects/psych/ psychosocial_care.htm (accessed 5 Dec 2004).

20 Turner J, McAvoy B, Luxford K, et al. Clinical practice guidelines for the psychosocial care of adults with cancer. Aust Fam Physician 2004;33:63-5.

21 Lockwood S. Evidence of me in evidence based medicine? BMJ 2004:329:1033-5.

22 Little M. "Better than numbers..." a gentle critique of evidence based medicine. In: Kerridge I, Jordens C, Sayers E-J, eds. Restoring humane values to medicine: a Miles Little reader. Sydney: Desert Pea Press, 2003:110.

23 Stove D. Anything goes. Sydney: Macleay Press, 1998:100-1.

24 Downie RS, Macnaughton J. Clinical judgment: evidence in practice. Oxford: Oxford University Press, 2000:33-5.

25 Goodman KW. Ethics and evidence based medicine: fallibility and responsibility in clinical science. Cambridge: Cambridge University Press, 2003:97.

26 Gifford F. Outcomes research and practice guidelines: upstream issues and epistemological issues. In: Boyle P, ed. Getting doctors to listen. Washington DC: Georgetown University Press, 2000:173-4.

27 Veatch R. Abandoning informed consent. Hastings Cent Rep 1995;25:5-12.

28 Veatch R. Technology assessment: inevitably a value judgment. In: Boyle P, ed. Getting doctors to listen. Washington DC: Georgetown University Press, 2000: 187-92.
29 Ashcroft R. Current epistemological questions in evidence based medicine. $J$ Med Ethics 2004;30:131-5 at 134.

30 Doust J, Del Mar C. Why do doctors use treatments that do not work? BM 2004;328:474

31 Alanen P. The problem of knowledge in medicine. In: Evans M, Louhiala P, Puustinen R, eds. Philosophy for medicine: applications in a clinical context. Oxford: Radcliffe Medical Press, 2004:34-6.

32 Strauss S, McAlister F. Evidence based medicine: a commentary on common criticisms. CMAJ 2000;163:837-41.

33 Vuorinen H. Philosophy of medicine and changing conditions. In: Evans M, Louhiala P, Puustinen R, eds. Philosophy for medicine: applications in a clinical context. Oxford: Radcliffe Medical Press, 2004:129-30

34 Edelson $\mathbf{P}$. Clinical practice guidelines: a historical perspective on their origins and significance. In: Boyle P, ed. Getting doctors to listen. Washington DC: Georgetown University Press, 2000:33-4.

35 Meulen R, Dickenson D. Into the hidden world behind evidence based medicine. Health Care Anal 2002;10:232-3.

36 Little M. Assignments of meaning in epidemiology. Soc Sci Med 1998:47: 1135-45.

37 Tanenbaum S. Say the right thing: communication and physician accountability in the era of medical outcomes. In: Boyle P, ed Getting doctors to listen. Washington DC: Georgetown University Press, 2000:212

38 Parker M. Whither our art? Clinical wisdom and evidence based medicine. Med Health Care Philos 2002;5:275-6.

39 Sackett DL, Rosenberg WMC, Muir Gray JA, et al. Evidence based medicine: what it is and what it isn't. BMJ 1996:312:71-2.

40 Willems D. Outcomes, guidelines, and implementation in France, the Netherlands, and Great Britain. In: Boyle P, ed. Getting doctors to listen. Washington DC: Georgetown University Press, 2000:157

41 Sanson-Fisher RW, Grimshaw JM, Eccles MP. The science of changing providers' behaviour: the missing link in evidence based practice. Med J Aust 2004; 180:205-6.

42 Michie S, Johnston M. Changing clinical behaviour by making guidelines specific. BMJ 2004;328:343-5

43 Hurwitz B. How does evidence based guidance influence determinations of medical negligence? BMJ 2004;329:1026-7.

44 Bolam v Friern Hospital Management Committee (1957) 1 WLR 586 (QBD).

45 Vos R, Houtepen R, Horstman K. Evidence based medicine and power shifts in health care systems. Health Care Anal 2002;10:325-6.

46 Saunders J. The practice of clinical medicine as an art and as a science. J Med Ethics 2000;26:18-22 at 21

47 Saunders J. Uncertainty in medicine. In: Evans M, Louhiala P, Puustinen R, eds. Philosophy for medicine: applications in a clinical context. Oxford: Radcliffe Medical Press, 2004:105-6.

48 Haynes RB, Devereaux P, Guyatt G. Physicians' and patients' choices in evidence based practice. BMJ 2002;324:1350.

49 Nelson JL. Clinical judgment versus outcomes research? In: Boyle P, ed. Getting doctors to listen. Washington DC: Georgetown University Press, 2000:196-203

50 Attia J, Nair B, Sibbritt D, et al. Generating pretest probabilities: a neglected area in clinical decision making. Med J Aust 2004;180:449-54.

51 Scott I. Estimating disease likelihood: a case of rubbery figures. Med J Aust 2004; 180:438-9.

52 Pettit P. A theory of freedom. Cambridge: Blackwell, 2001:6.

53 Boyle P, Callahan D. Physicians' use of outcomes data: moral conflicts and potential resolutions. In: Boyle P, ed. Getting doctors to listen. Washington DC: Georgetown University Press, 2000:18.

54 Gabbay J, May A. Evidence based guidelines or collectively constructed "mindlines?" Ethnographic study of knowledge management in primary care. BMJ 2004:329:1013-17.

55 Wainwright $\mathbf{P}$. The aesthetics of clinical practice. In: Evans $M$, Louhiala P, Puustinen R, eds. Philosophy for medicine: applications in a clinical context. Oxford: Radcliffe Medical Press, 2004:84-5. 